\title{
Physician and Family Discussions about Driving Safety: Findings from the LongROAD Study
}

\author{
Marian E. Betz, MD, MPH, Leon Villavicencio, MPH, Deepika Kandasamy, MPH, \\ Tara Kelley-Baker, PhD, Woon Kim, PhD, Carolyn DiGuiseppi, MD, PhD, \\ Thelma J. Mielenz, PT, PhD, David W. Eby, PhD, Lisa J. Molnar, PhD, \\ Linda Hill, MD, MPH, David Strogatz, PhD, David B. Carr, MD, and \\ Guobua Li, MD, DrPH, on behalf of the LongROAD Research Team
}

Background: Older adult drivers may experience decreases in driving safety with age or health status change. Discussing driving safety may help them plan for driving restriction and eventual cessation. Here, we sought to examine conversations between older adults and their family members and physicians.

Methods: In this multi-site cross-sectional analysis of baseline data from the AAA Longitudinal Research on Aging Drivers (LongROAD) cohort study, we measured the prevalence and characteristics of family and physician driving discussions. We examined associations between having driving discussions and participant characteristics using multivariate logistic regression.

Results: Of 2990 current drivers aged 65 to 79 years (53\% female, $85.5 \%$ White), only $14.2 \%$ reported discussing driving safety with family and $5.5 \%$ had discussions with physicians. Men (adjusted OR, 1.32; 95\% CI, 1.05 to 1.66) and those with Master's degrees or higher (adjusted 0R, 1.65; 95\% CI, 1.27 to 2.13) more often had family discussions. Those with at least a Master's degree were also more likely to speak with their physician (adjusted OR, 1.77; 95\% CI, 1.17 to 2.68).

Conclusion: Few older adults had driving safety conversations with their family or physicians. Practical and effective interventions are needed to engage family and physicians in assisting older adults with risk assessment and driving cessation planning to maintain mobility and well-being. (J Am Board Fam Med 2019;32:607-613.)

Keywords: Automobile Driving, Cohort Studies, Communication, Cross-Sectional Studies, Logistic Models, Physician-Patient Relations, Risk Assessment

Medical conditions, medications, and physiologic changes from aging can affect driving ability. ${ }^{1}$ Driving safety, self-regulation, and cessation are issues many older adults eventually face. ${ }^{2}$ Family and physicians may influence driving decisions, de-

This article was externally peer reviewed.

Submitted 5 November 2018; revised 15 January 2019; accepted 15 January 2019.

From the Department of Emergency Medicine, University of Colorado School of Medicine, Aurora, CO (MEB, DK); AAA Foundation for Traffic Safety, Washington, DC (LV, TK-B, WK); Department of Epidemiology, Colorado School of Public Health, University of Colorado Anschutz Medical Campus, Aurora, CO (CD); Department of Epidemiology, Mailman School of Public Health, Columbia University, New York, NY (TJM, GL); Center for Injury Epidemiology and Prevention, Columbia University Medical Center, New York, NY (TJM, GL); University of Michigan Transportation Research Institute and Center for Advancing pending on their availability and involvement and the older adult's counseling preferences. ${ }^{3-5}$

Prior research showed that drivers aged $\geq 50$ years preferred discussing driving with family ver-

Transportation Leadership and Safety, Ann Arbor, MI (DWE, LJM); Department of Family Medicine and Public Health, University of California-San Diego, San Diego CA (LH); Bassett Research Institute, Bassett Healthcare Network, Cooperstown, NY (DS); Departments of Medicine and Neurology, Washington University School of Medicine, St. Louis, MO (DBC); Department of Anesthesiology, Columbia University College of Physicians and Surgeons, New York, NY (GL).

Funding: This research was supported by the AAA Foundation for Traffic Safety (Washington, DC) through the Longitudinal Research on Aging Drivers (LongROAD) Project and by a Paul Beeson Career Development Award Program [The National Institute on Aging; AFAR; The John A. Hartford Foundation; and The Atlantic Philanthropies; Grant K23AG043123]. GL and TLM were 
sus nonfamily. ${ }^{6}$ In another driving survey, $64 \%$ of community-dwelling older adults were open to family discussion but fewer to family (32\%) or physicians (44\%) making driving cessation decisions. ${ }^{7}$ How much interaction older adults have with family often determines their comfort with family involvement in driving decisions. ${ }^{8}$

Yet health care providers also play key roles in driving safety and cessation. ${ }^{1}$ One study found that married older adults preferred hearing first from their spouse and adult children but also desired conversations with their physician. ${ }^{6}$ Those indicating physicians as first choice believed the physician could judge their driving capabilities. However, the study's physician participants were reluctant to partake in driving decisions. Many physicians report assessing driving fitness or discussing driving with their older patients, but only with some patients and not frequently with each of them. ${ }^{1,9}$ A retrospective medical record review documented that physicians discussed driving with only $8 \%$ to $22 \%$ of patients within a 12 -month period. ${ }^{10}$

The LongROAD study, a multi-site longitudinal cohort study of older drivers, offers opportunities to examine the prevalence of driving discussions with family and providers in a larger sample than prior work. Understanding the frequency of such discussions and the demographic and driving characteristics associated with them may enhance communication strategy development and refinement.

\section{Methods}

\section{Design and Participants}

This cross-sectional study utilized baseline data from participants enrolled at the 5 LongROAD sites in California, Colorado, Michigan, Maryland, and New York; LongROAD was designed to examine driving behaviors and outcomes (and their associations with health and functional variables) in a large cohort over time, and the study is described in detail elsewhere. ${ }^{11}$ Research assistants identified

also supported by Grant 1 R49 [Centers of Disease Control and Prevention; Grant CE002096]. The contents of the manuscript are solely the responsibility of the authors and do not necessarily reflect the official views of the funding agencies.

Conflict of interest: none declared.

Corresponding author: Marian E. Betz, MD, MPH, University of Colorado School of Medicine; 12401 E. 17th Ave B-215; Aurora, CO 80045 (E-mail: marian.betz@ucdenver. edu). potentially eligible participants from primary care clinic rosters and assessed eligibility and interest by phone. Eligible individuals were 65 to 79 years of age, possessed valid driver's licenses, drove at least once weekly on average, drove 1 car (1996 model or newer) primarily ( $>80 \%$ of the time), and had no significant cognitive impairment (verified through medical records at some sites and the Six-Item Screener at all sites). ${ }^{12}$ Research assistants obtained written informed consent at the in-person enrollment visit. Institutional Review Boards at each site approved the study.

\section{Measures}

This analysis used baseline data from all LongROAD participants for variables surrounding driving discussions (Have you ever [spoken to your family doctor or any other doctor]/[had a discussion with a family member] about your driving safety?) and driving limitation recommendations. Additional variables included demographic characteristics, self-reported health condition-related driving reduction in the past year and driving experiences (Table 1). Drivers were asked to rate their average driving ability and comfort driving on a separate scale of 1 (poor ability/not at all comfortable) to 7 (excellent ability/completely comfortable). They reported driving lapses in attention, errors, and violations on separate scales from 1 (never) to 6 (nearly all the time). Strategic self-regulation was measured as the sum of 13 binary variables on whether they indicated avoiding behaviors due to concerns regarding their cognitive, physical, perceptual performance as it relates to driving. Tactical self-regulation was measured as the sum of 7 binary variables indicating behavior avoidance due to concerns regarding their cognitive, physical, or perceptual performance as it relates to driving.

\section{Analysis}

We described family and physician driving discussion prevalence with $95 \%$ confidence intervals (95\% CI). We used $\chi^{2}$ or Fisher's exact test for categorical variables and 1-way ANOVA for continuous variables, in comparing demographic characteristics and family and physician discussions. We utilized multivariable logistic regression, identifying variables associated with discussions using a $P<.20$ cutoff for initial model inclusion and backwards elimination for model optimization. 
Table 1. Participant Characteristics by Reported Discussions with Family Members or Physicians $(n=2990)$

\begin{tabular}{|c|c|c|c|c|c|}
\hline \multirow[b]{2}{*}{ Characteristic } & \multirow[b]{2}{*}{$\mathbf{n}$} & \multicolumn{2}{|c|}{ With Family $(n=426)$} & \multicolumn{2}{|c|}{ With Physician $(n=165)$} \\
\hline & & $\%$ & $95 \% \mathrm{CI}$ & $\%$ & $95 \%$ CI \\
\hline Total & 2990 & 14.2 & 13.0 to 15.5 & 5.5 & 4.7 to 6.3 \\
\hline \multicolumn{6}{|l|}{ Age (years)* } \\
\hline 65 to 69 & 1243 & 13.8 & 11.9 to 15.8 & 5.6 & 4.3 to 6.8 \\
\hline 70 to 74 & 1037 & 12.5 & 10.5 to 14.6 & 5.5 & 4.1 to 6.9 \\
\hline 75 to 79 & 710 & 17.5 & 14.7 to 20.3 & 5.5 & 3.8 to 7.2 \\
\hline \multicolumn{6}{|l|}{ Gender* } \\
\hline Male & 1404 & 15.9 & 14.0 to 17.8 & 5.6 & 4.4 to 6.8 \\
\hline Female & 1586 & 12.8 & 11.2 to 14.4 & 5.4 & 4.3 to 6.5 \\
\hline \multicolumn{6}{|l|}{ Race } \\
\hline White & 2557 & 14.6 & 13.2 to 16 & 5.5 & 4.6 to 6.4 \\
\hline Black & 212 & 11.3 & 7.1 to 15.6 & 5.7 & 2.5 to 8.8 \\
\hline Asian & 64 & 14.1 & 5.5 to 22.6 & 7.8 & 1.2 to 14.4 \\
\hline Other & 157 & 12.7 & 7.5 to 18.0 & 4.5 & 1.2 to 7.7 \\
\hline \multicolumn{6}{|l|}{ Hispanic } \\
\hline Yes & 83 & 13.3 & 6.0 to 20.6 & 1.2 & 0.0 to 3.6 \\
\hline No & 2794 & 14.5 & 13.2 to 15.8 & 5.8 & 4.9 to 6.6 \\
\hline \multicolumn{6}{|l|}{ Education $^{\mathrm{b}}$} \\
\hline$\leq$ Some college & 1062 & 12.0 & 10.0 to 13.9 & 5.2 & 3.8 to 6.5 \\
\hline Bachelors & 698 & 12.0 & 9.6 to 14.4 & 4.3 & 2.8 to 5.8 \\
\hline$\geq$ Masters & 1221 & 17.5 & 15.4 to 19.7 & 6.6 & 5.2 to 7.9 \\
\hline \multicolumn{6}{|l|}{ Income } \\
\hline$\leq \$ 49,999$ & 775 & 12.6 & 10.3 to 15 & 6.2 & 4.5 to 7.9 \\
\hline$\$ 50,000$ to $\$ 79,999$ & 719 & 14.3 & 11.8 to 16.9 & 7.0 & 5.1 to 8.8 \\
\hline$\$ 80,000$ to $\$ 99,999$ & 431 & 14.8 & 11.5 to 18.2 & 5.8 & 3.6 to 8.0 \\
\hline$\geq \$ 100,000$ & 959 & 16.2 & 13.8 to 18.5 & 4.1 & 2.8 to 5.3 \\
\hline \multicolumn{6}{|l|}{ Paid employment } \\
\hline Yes & 904 & 13.4 & 11.3 to 15.7 & 4.2 & 2.9 to 5.5 \\
\hline No & 2084 & 14.5 & 13.0 to 16.1 & 6.1 & 5.1 to 7.1 \\
\hline \multicolumn{6}{|l|}{ Marital status* } \\
\hline Married/living with partner & 1974 & 15.3 & 13.7 to 16.9 & 5.5 & 4.5 to 6.5 \\
\hline Separated/divorced & 608 & 11.3 & 8.8 to 13.9 & 6.1 & 4.2 to 8.0 \\
\hline Widowed & 378 & 13.0 & 9.6 to 16.4 & 4.5 & 2.4 to 6.6 \\
\hline \multicolumn{6}{|l|}{ Traffic event ${ }^{\mathbb{I}}$} \\
\hline Yes & 703 & 16.1 & 13.4 to 18.8 & 5.1 & 3.5 to 6.8 \\
\hline No & 2286 & 13.7 & 12.3 to 15.1 & 5.6 & 4.7 to 6.5 \\
\hline \multicolumn{6}{|l|}{ Driving reduction $^{+, \S}$} \\
\hline No reduction & 2442 & 13.4 & 12.0 to 14.7 & 5.0 & 4.1 to 5.9 \\
\hline For self-regulation & 173 & 26.6 & 20.0 to 33.2 & 13.9 & 8.7 to 19.0 \\
\hline For other reason(s) & 355 & 13.5 & 10.0 to 17.1 & 5.4 & 3.0 to 7.7 \\
\hline \multicolumn{6}{|l|}{ Other people... } \\
\hline \multicolumn{6}{|l|}{...depend on you for rides } \\
\hline Yes & 762 & 15.9 & 13.3 to 18.5 & 5.2 & 3.7 to 6.8 \\
\hline No & 2222 & 13.7 & 12.3 to 15.1 & 5.6 & 4.6 to 6.5 \\
\hline \multicolumn{6}{|l|}{...can give you rides } \\
\hline Yes & 2826 & 14.2 & 12.9 to 15.5 & 5.7 & 4.9 to 6.6 \\
\hline No & 148 & 13.5 & 8.0 to 19.0 & 2.0 & 0 to 4.3 \\
\hline
\end{tabular}

Continued 
Table 1. Continued

\begin{tabular}{lrr}
\hline Driving scales $^{\|}$ & Mean (SD) & Mean (SD) \\
\hline Self-rated average ability $^{\dagger, \S}$ & $5.65(0.73)$ & $5.67(0.75)$ \\
Errors $^{\dagger}$ & $1.54(0.34)$ & $1.47(0.35)$ \\
Violations $^{\dagger}$ & $1.7(0.41)$ & $1.61(0.37)$ \\
Strategic Self Regulation $^{\dagger, \$}$ & $2.96(2.42)$ & $3.22(2.56)$ \\
Tactical Self Regulation $^{\dagger, \ddagger}$ & $3.18(1.7)$ & $3.26(1.68)$ \\
\hline
\end{tabular}

Family discussion prevalence differs by characteristic at $P<.05^{*}$ or $P<.001^{\dagger}$ via $\chi^{2}$ tests; physician discussion prevalence differs at $P<.05^{\ddagger}$ or $P<.001^{\S}$ via $\chi^{2}$ tests or Fisher's exact tests.

I" Traffic event" was $\geq 1$ motor vehicle crash, police stop, or traffic ticket within the past year.

"See Methods for full description of scales.

CI, confidential interval; SD, standard deviation.

\section{Results}

Of 2990 total LongROAD participants, approximately half were female and 65 to 69 years old; most were White and non-Hispanic. A majority were married and had household incomes $\geq \$ 50,000$ yearly and Bachelor's degrees or higher (Table 1). Overall, 337 participants (11.3\%) reported driving reduction due to a health problem in the past year. Only $2.2 \%$ reported that, in the past year, someone had recommended limiting their driving.

Overall, $17.3 \%$ of participants reported ever having driving discussions with family or physicians. They were more likely to have spoken with family (14.2\%; Table 1) than physicians (5.5\%). Seventyfour participants $(2.5 \%)$ had conversations with both. Similar patterns manifested across gender and age. Men and those aged 75 to 79 years (vs younger age groups) were significantly more likely to speak with family (Table 1). Most family conversations were initiated by family $(60.6 \%)$, while most physicians conversations were initiated by older drivers $(55.0 \%)$. When asked what triggered a family discussion, most said driving safety concerns (64.8\%), followed by health issue $(22.3 \%)$, driving infraction $(8.7 \%)$, and crash $(8.7 \%)$. Patterns were similar across gender and age (data not shown).

Common outcomes of physician discussions were medical or physical assessment (41.8\%), education or advice $(38.2 \%)$, follow-up visits to monitor health concerns $(32.2 \%)$, and medical treatment $(29.0 \%$; Figure 1). Few reported referrals for driving assessment to a licensing bureau (3.6\%) or occupational therapist (2.4\%). Nearly one quarter $(22.5 \%)$ said no action resulted from these conversations.

Driving discussions with family were significantly associated with demographic characteristics (Table
2). Men, participants with Master's degrees and higher (vs less than Bachelor's degrees), and those who reduced driving for self-regulatory reasons in the past year were more likely to have driving conversations with family as well as those with lower self-rated driving ability, higher strategic self-regulation (ie, pretrip decisions attributed to self regulation), and more driving errors or violations. Similar characteristics were associated with having driving discussions with physicians (Table 2).

\section{Discussion}

In the large LongROAD cohort of older drivers, most had not discussed driving with their family or physician. Conversations that did occur were more common with family than with physicians, perhaps reflecting the relatively good health of participants. Few older drivers having physician discussions were referred for driving assessment.

Older drivers who anticipate and prepare for driving cessation experience better health outcomes, emphasizing the benefits of advance planning. ${ }^{3}$ Yet few participants had discussed driving safety with family or physicians, which is consistent with past research and may reflect avoidance of this sensitive subject ${ }^{13}$ or unawareness that many older adults are unable to drive for the last years of life. ${ }^{2}$ Physicians in particular may believe that conversations about driving safety adversely affects patient-physician relationships, especially when they include recommendations for driving cessation. ${ }^{14-16}$ Physicians may also feel they lack training or resources regarding driving assessments, licensing laws, or linkages to older driver testing or education programs. ${ }^{17,18}$ Yet physicians do have obligations to protect patient and public safety, ${ }^{19}$ and available resources can help them with these difficult situations. ${ }^{1,20}$ 
Figure 1. Reported outcomes of discussions with physicians, by age and gender $(n=165)$.

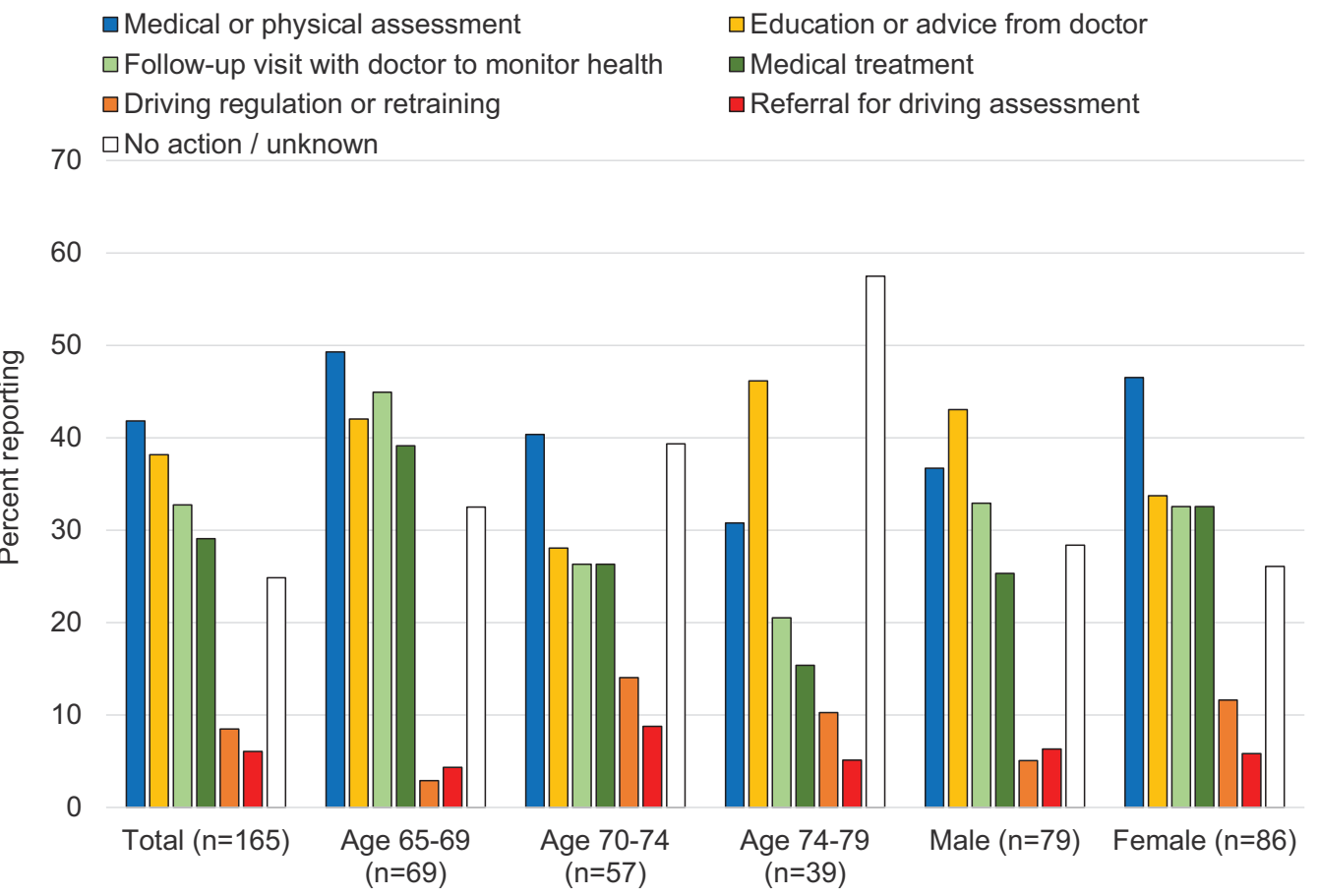

Participants were twice as likely to discuss driving safety with family as with physicians. While some resources exist to help physicians address this topic in clinical settings, ${ }^{1}$ there are fewer available for families, who may also benefit from public awareness campaigns and education. ${ }^{13,21}$ In addition, physicians should pay special attention to older adults who are widowed, single, or without family, since this population may not have social support in driving matters.

Driving discussions with family were more likely to occur when participants were male and more educated. Gender-related findings may reflect that, similar to past studies, men may want to maintain a traditional provider role and continue driving later in life (hence prompting family discussions), while women are willing to relinquish driving earlier. ${ }^{22}$ Gender was not associated with physician conversations, but those with higher education and who self-restricted their driving often discussed driving safety with physicians. Generally, previous research shows physicians and older drivers tend not to initiate driving conversations until specific "red flags," (eg, crashes) manifest. ${ }^{8}$ Circumstances of conversation initiation with physicians were not considered in the LongROAD study and should be examined in future research.
Very few participants had driving discussions resulting in referral for driving assessment. Such evaluations are often unavailable, though they are often recommended and useful. ${ }^{23}$ Creating and testing triage tools to identify older adults who may benefit from driving assessments is vital, as reliable tests or combinations of tests have not yet been identified. ${ }^{24}$ Physicians desire simple protocols to screen older drivers so developing such resources may help them to properly address older adult driving in clinical settings. ${ }^{17,25}$

\section{Limitations}

Study limitations include an inability to determine when participants had conversations with family or physicians. The LongROAD study's longitudinal follow-up may help us better address the temporal relationship between discussions and subsequent driving behaviors, including attention to patterns by age or gender. Since the LongROAD study recruited active primary care patients, the prevalence of physician conversations may be higher than in the general population. In addition, findings were based on a sample of mainly welleducated, White, non-Hispanic drivers aged 65 to 79 years and may not be generalizable to other populations. Findings also are not generalizable 
Table 2. Factors Associated with Older Adults Reporting Driving Discussions with Family Members or Physicians

\begin{tabular}{|c|c|c|}
\hline Characteristic & Family member AOR (95\%CI) & Physician AOR (95\%CI) \\
\hline \multicolumn{3}{|l|}{ Age (years) } \\
\hline 65 to 69 & 1.00 (Ref) & - \\
\hline 70 to 74 & $0.86(0.6$ to 1.12$)$ & - \\
\hline 75 to 79 & $1.16(0.88$ to 1.53$)$ & - \\
\hline \multicolumn{3}{|l|}{ Gender } \\
\hline Male & $1.32(1.05 \text { to } 1.66)^{*}$ & - \\
\hline Female & 1.00 (Ref) & - \\
\hline \multicolumn{3}{|l|}{ Hispanic } \\
\hline Yes & - & $0.24(0.03$ to 1.75$)$ \\
\hline No & - & 1.00 (Ref) \\
\hline \multicolumn{3}{|l|}{ Education } \\
\hline$\leq$ Some college & 1.00 (Ref) & 1.00 (Ref) \\
\hline Bachelors & $0.92(0.67$ to 1.27$)$ & $1.03(0.64$ to 1.68$)$ \\
\hline$\geq$ Masters & $1.65(1.27 \text { to } 2.13)^{+}$ & $1.77(1.17 \text { to } 2.68)^{+}$ \\
\hline \multicolumn{3}{|l|}{ Income } \\
\hline$\leq \$ 49,999$ & - & 1.00 (Ref) \\
\hline$\$ 50,000$ to 79,999 & - & $1.13(0.73$ to 1.75$)$ \\
\hline$\$ 80,000$ to $\$ 99,999$ & - & $0.91(0.53$ to 1.57$)$ \\
\hline$\geq \$ 100,000$ & - & $0.69(0.42$ to 1.13$)$ \\
\hline \multicolumn{3}{|l|}{ Employed (paid) } \\
\hline No & - & 1.00 (Ref) \\
\hline Yes & - & $0.75(0.51$ to 1.11$)$ \\
\hline \multicolumn{3}{|l|}{ Traffic event ${ }^{\S}$} \\
\hline No & 1.00 (Ref) & - \\
\hline Yes & $1.27(0.99$ to 1.63$)$ & - \\
\hline \multicolumn{3}{|l|}{ Driving reduction } \\
\hline None & 1.00 (Ref) & 1.00 (Ref) \\
\hline Self-regulation & $1.68(1.12 \text { to } 2.53)^{\dagger}$ & $2.10(1.25 \text { to } 3.50)^{+}$ \\
\hline Other reason(s) & $0.94(0.66$ to 1.33$)$ & $1.14(0.69$ to 1.90$)$ \\
\hline \multicolumn{3}{|l|}{ Others... } \\
\hline \multicolumn{3}{|l|}{...dependent for rides } \\
\hline No & 1.00 (Ref) & - \\
\hline Yes & $1.23(0.96$ to 1.58$)$ & - \\
\hline \multicolumn{3}{|l|}{...can give rides } \\
\hline No & - & 1.00 (Ref) \\
\hline Yes & - & 3.13 (0.98 to 10.04$)$ \\
\hline \multicolumn{3}{|l|}{ Driving scales ${ }^{\mathbb{T I}}$} \\
\hline Self-rated driving ability & $0.67(0.56 \text { to } 0.79)^{\neq}$ & $0.75(0.59 \text { to } 0.95)^{*}$ \\
\hline Errors & $1.65(1.13 \text { to } 2.39)^{*}$ & - \\
\hline Violations & $1.45(1.06 \text { to } 1.99)^{*}$ & - \\
\hline Strategic self-regulation & $1.09(1.04 \text { to } 1.15)^{+}$ & $1.10(1.03 \text { to } 1.19)^{\dagger}$ \\
\hline Tactical Self-regulation & - & - \\
\hline
\end{tabular}

AOR, adjusted odds ratio (adjusted for all other characteristics in AOR model); CI, confidential interval. Italics indicate statistically significant results.

${ }^{*} P<.05 ;{ }^{\dagger} P<.01 ;{ }^{\ddagger} P<.001$.

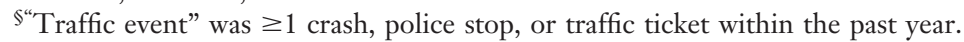

"See Methods for full description of scales.

to older adults with cognitive impairment, who were excluded from the parent LongROAD study but are a population at risk of adverse driving outcomes.

\section{Conclusion}

In this study, most older adults did not report past driving discussions with family or physicians. Family and physicians may benefit from resources that ad- 
dress driving safety in the older population. Future interventions should use health education techniques targeting both families and physicians to raise awareness and provide information about this impending issue so they might knowledgeably participate in maintaining and improving older adults' quality of life.

We thank Howard Andrews, Vanya Jones, Robert Santos, David LeBlanc, and Lindsay Ryan for their work as part of the LongROAD Research Team.

To see this article online, please go to: http://jabfm.org/content/ 32/4/607.full.

\section{References}

1. Pomidor A. Clinician's guide to assessing and counseling older drivers. 3rd ed. Washington, DC: American Geriatrics Society and National Highway Traffic Safety Administration; 2016.

2. Foley DJ, Heimovitz HK, Guralnik JM, et al. Driving life expectancy of persons aged 70 years and older in the United States. Am J Public Health 2002; 92:1284-1289.

3. Betz ME, Scott K, Jones J, et al. "Are you still driving?" Meta-synthesis of older adults' preferences for communication with healthcare providers about driving. Traffic Inj Prev 2016;17:367-373.

4. Liddle J, Gustafsson L, Mitchell G, et al. A difficult journey: Reflections on driving and driving cessation from a team of clinical researchers. Gerontologist 2017;57:82-88.

5. Meuser TM, Carr DB, Unger EA, et al. Family reports of medically impaired drivers in Missouri: Cognitive concerns and licensing outcomes. Accid Anal Prev 2015;74:17-23.

6. D'Ambrosio L, Coughlin J, Mohyde M, et al. Family matter: Older drivers and the driving decision. Transport Res Rec 2007;2009:23-39.

7. Lum HD, Brown JB, Juarez-Colunga E, et al. Physician involvement in life transition planning: A survey of community-dwelling older adults. BMC Fam Pract 2015;16:92.

8. Betz ME, Jones J, Petroff E, Schwartz R. "I wish we could normalize driving health:" A qualitative study of clinician discussions with older drivers. J Gen Intern Med 2013;28:1573-1580.

9. Huseth-Zosel AL, Sanders G, O'Connor M. Predictors of health care provider anticipatory guidance provision for older drivers. Traffic Inj Prev 2016;17: $815-820$

10. Betz ME, Kanani H, Juarez-Colunga E, et al. Discussions about driving between older adults and pri- mary care providers. J Am Geriatr Soc 2016;64: $1318-23$.

11. Li G, Eby DW, Santos R, et al. Longitudinal Research on Aging Drivers (LongROAD): Study design and methods. Injury Epidemiol 2017;4:22.

12. Callahan CM, Unverzagt FW, Hui SL, et al. Sixitem screener to identify cognitive impairment among potential subjects for clinical research. Med Care 2002;40:771-781.

13. Eby DW, Molnar LJ, Shope JT, et al. Improving older driver knowledge and self-awareness through self-assessment: The driving decisions workbook. J Safety Res 2003;34:371-381.

14. Dugan E. The driving dilemma: The complete resource guide for older drivers and their families. New York, NY: William Morrow Paperbacks; 2006.

15. Jang RW, Man-Son-Hing M, Molnar FJ, et al. Family physicians' attitudes and practices regarding assessments of medical fitness to drive in older persons. J Gen Intern Med 2007;22:531-543.

16. Huseth-Zosel AL, Sanders G, O'Connor M, et al. Health care provider mobility counseling provision to older adults: A rural/urban comparison. J Community Health 2016;41:1-10.

17. Leinberger RL, Janz NK, Musch DC, et ak. Discussing driving concerns with older patients: I. vision care providers' attitudes and behaviors. JAMA Ophthalmol 2013;131:205-212.

18. Keskinen E. Education for older drivers in the future. IATSS Res 2014;38:14-21.

19. Code of Medical Ethics Opinion 8.2: Impaired Drivers \& Their Physicians. Available from: https:// www.ama-assn.org/delivering-care/ethics/impaireddrivers-their-physicians. Accessed January 8, 2019.

20. Senior Driving: State Laws. 2019. Available from: https://seniordriving.aaa.com/states/. Accessed January 8, 2019.

21. Adler G. Driving decision-making in older adults with dementia. Dementia 2010;9:45-60.

22. Choi M, Adams KB, Kahana E. Self-regulatory driving behaviors: Gender and transportation support effects. J Women Aging 2013;25:104-118.

23. Betz ME, Dickerson A, Coolman T, et al. Driving rehabilitation programs for older drivers in the United States. Occup Ther Health Care 2014;28: 306-317.

24. Dickerson AE. Screening and assessment tools for determining fitness to drive: A review of the literature for the pathways project. Occup Ther Health Care 2014;28:82-121.

25. Bogner HR, Straton JB, Gallo JJ, et al. The role of physicians in assessing older drivers: Barriers, opportunities, and strategies. J Am Board Fam Pract 2004; $17: 38-43$. 